\title{
Could Obesity be Linked to Falls in Older Adults?
}

\author{
Sheng Hui Kioh ${ }^{1,2}$, Sumaiyah Mat ${ }^{1}$, Phyo Kyaw Myint ${ }^{2}$ and Maw Pin Tan*1,3,4 \\ ${ }^{1}$ Ageing and Age-Associated Disorders Research Group, University of Malaya, Kuala Lumpur, Malaysia \\ ${ }^{2}$ Ageing Clinical \& Experimental Research Unit, Institute of Applied Health Sciences, University of Aberdeen, United Kingdom \\ ${ }^{3}$ Department of Medicine, Faculty of Medicine, University of Malaya, Kuala Lumpur, Malaysia \\ ${ }^{4}$ Department of Medical Sciences, School of Healthcare and Medical Sciences, Sunway University, Bandar Sunway, Malaysia
}

Received: 制: January 03, 2019; Published: 制: January 11, 2019

*Corresponding author: Maw Pin Tan, Department of Medicine, Faculty of Medicine, University of Malaya, 50603Kuala Lumpur, Malaysia

\section{Introduction}

An increase in life expectancy has led to the rapid growth in older population globally, resulting in an increase in age-associated diseases and disability. This place increasing pressure on societies as well as the healthcare systems. To add to this issue, increasingly sedentary lifestyles and the accessibility to cheap, highly calorific foods, has also led to an obesity epidemic globally. The increased prevalence of obesity in the older adult population is now considered a major public health problem. However, obesity in older adults are often underestimated due to the uncertainty of benefits over the risk of weight reduction programmed in older adults. Generally, it is widely accepted that obesity is often associated with multiple health conditions including type 2 diabetes mellitus, hypertension, sleep apnoea, hypercholesteremia, cancer [1,2] as well as several age-associated diseases such as osteoarthritis, dementia and cognitive impairment [3]. Additionally, some studies suggest that obesity may have an impact on falls in older adults, however, this relationship is not adequately established. At least one in five older adults aged 65 years and above fall each year and falls has been identified as the second leading cause of unintentional deaths among older adults $[4,5]$.

Although falls are considered multifactorial, previous studies have proposed that older adults with obesity, primarily measured with the Body Mass Index (BMI), have a higher rate of falling compared to older adults without obesity [6,7]. Others have, conversely, suggested that being obese is a protective factor against falls [8]. Given the conflicting evidence on the relationship between obesity and falls, this clinical review aims to present published evidences for the contemporary literature (over past 10 years) definition of obesity, prevalence of obesity and falls and association between obesity and falls risk focusing on older adults. We also propose areas for future research.

\section{Method}

We performed a literature search using the two electronic databases, PubMed and Google Scholar, to search for articles published from 2008 to the present, containing the terms ("obese" OR "obesity" OR "adiposity") AND ("falls" OR "accidental fall") AND ("aged" OR "aging" OR "older people") within their titles, abstracts or keywords.

\section{Definition and Epidemiology of Obesity}

Obesity is defined as abnormal or excessive fat accumulation in the body that is detrimental to the health [9]. Published evidence has suggested various indices to quantify obesity such as waist circumference, body fat percentage, waist hip ratio and skinfold thickness. The universally accepted measure by which obesity often defined, however, remains the BMI. According to World Health Organization (WHO), a person with a BMI $\geq 30 \mathrm{~kg} / \mathrm{m} 2$ is classified as obese [9]. There is currently no specific definition of obesity in older adults, despite the recent published evidence suggesting the potential inappropriateness of using BMI as a measure to determine the presence of obesity in older adults due to age-associated body composition changes. The published prevalence of obesity in older adults using BMI definitions that have been reported in the previous literature varies widely between geographical regions. For example, a recent published study in India among 981 adults aged 60 years and above found that $4.6 \%$ of the population fulfilled the BMI criteria for obesity [2] while Hajek et al found that $40.0 \%$ of the German population aged 75 years old and above exceeded the BMI cut-off for obesity [10].

Discrepancies in the prevalence of obesity is likely to be attributed to diet and lifestyle factors. It was, hence, suggested that the Asian population consumed a lower fat diet, were physically 
more active and had higher determination in controlling their weight compared to the Western population based to explain the apparent discrepancy in levels of obesity among older adults between the two regions [11]. Obesity in older adults, however, is now considered a heterogenous condition with the definition of sarcopenic obesity as a new pathological condition. Sarcopenia obesity is defined as the presence of both sarcopenia and obesity in which an older person experiences excess accumulation of adipose tissue with an associated decline in both muscle mass and physical performance [12]. With obesity or sarcopenia both independently linked to poorer quality of life, morbidity and mortality, both sarcopenia and obesity act synergistically leading to a greater negative effect on overall health and survival $[12,13]$.

\section{Epidemiology of Falls}

While an increasing absolute number of older adults is observed to fall each year, fall rates do appear to vary with the geographical location. A cross sectional study from India reported that $28.8 \%$ of the population had fallen at least once whereas in Thailand and Brazil the prevalence of fall was found to be $26.1 \%$ and $28.1 \%$ respectively [14-16]. The prevalence of falls from published reports from Western Europe and North America have been higher at 20.042.0\% [17-21]. Additionally, a recent study in Malaysia suggested that falls prevalence differ by age group where the prevalence for the overall population aged 55 years and above was $22.8 \%, 65$ years and above was $24.5 \%$ and 75 years and above was $32.2 \%$ [5]. The prevalence of falls also differs according to the population studied. For example, falls prevalence among community-dwelling older adults aged 60 years and above was $21.2 \%$ [5] while a study conducted among institutionalized older adults aged 60 years and above revealed a prevalence of $32.8 \%$ [22]. A separate study conducted among older adults in a tertiary centre found a lower prevalence of $18.8 \%$ [23]. Longer term studies or prospective studies, however, have clearly demonstrated increased risk of falls among older adults living in institutions with prevalence of falls of $36.0 \%$ [24] compared to those living in the community with prevalence of falls of $19.1 \%$ [25].

While studies now raise doubts about the increased prevalence of falls in institutions, Karine, et al. proposed that institutionalized older adults have poorer mental health which increases their social isolation as well as their functional capability leading to a higher likelihood of falling compared to community-dwelling older adults [26]. Falls are usually multifactorial with increasing age, sex, history of fall, number of medications, gait and balance disturbances and environmental hazards considered common risk factors $[27,28]$. Additionally, older adults with cardiovascular diseases, musculoskeletal system diseases, nervous system diseases and respiratory system diseases are more likely to fall compared to healthy older individuals $[29,30]$. Consequences associated with falls among older adults can be potentially serious, with reduction in confidence levels, increased dependency, longer stays in hospitals, fractures and pre-mature deaths affecting a sizeable proportion of those who fall [30]. These complications do not impact on the older adult along but also affects families and society in the terms of healthcare expenditure, caregiver burden and emotional stress. [31].

\section{Obesity and Falls Risk}

Despite falls being common and obesity now increasing in prevalence among older adults, few studies have been conducted to date to examine the relationship between the two. Three crosssectional studies have suggested a positive association between with falls and older adults [6,32,33]. Results of the above studies indicate that older adults with $\mathrm{BMI} \geq 30 \mathrm{~kg} / \mathrm{m} 2$ have a $10-78 \%$ increase in odds of falling. It was suggested that older adults with a higher BMI have poorer postural balance leading to an increased sway compared to older adults with normal BMI [34]. Additionally, obesity may also favour falls with the presence of some mediators such as consumption of sedation for sleep and anti-depressants that leads to dizziness and increased sleepiness [35]. In contrast, Sheehan et al found that in older adults the presence of obesity was protective against falls [36]. They suggested that obese older adults with BMI $\geq 30 \mathrm{~kg} / \mathrm{m}^{2}$ were less likely to experience a fall due to their tentative gait pattern with a slower walking speed and increased support base. This assumption, however, does not seem to apply to older adults with BMI $\geq 35 \mathrm{~kg} / \mathrm{m} 2$ who have impaired dynamic stability. It may be that older adults with a slightly higher BMI may benefit from the protective effect against falls and only those with extremely high BMI are at a higher risk of falls. This indeed, may suggest that the presence of an apparent obesity paradox regarding falls among older adults. Researchers in other fields have reported an "obesity paradox" such as lower mortality rates in obese patients compared to non-obese patients with cardiovascular diseases. This obesity paradox was replicated in numerous non-communicable conditions such as diabetes, chronic obstructive pulmonary diseases, kidney diseases and stroke.

However, recent literature on obesity suggests that BMI may not be an appropriate measurement to determine the presence of obesity especially among the older adults due to the presence of age-related changes such as loss of height due to vertebral compression and body composition changes $[37,38]$. The use of the BMI amplifies the effect of age-related loss of height as the actual value for height is first squared before the index is calculated [39], therefore leading to over-estimation of the BMI in older adults with loss of height. Ageing is also associated with increased body fat and a reduction in lean body mass which consists of both muscle bulk and bone density. Fat weighs significantly less than its equivalent volume in muscle or bone. Hence an older individual with osteoporosis and sarcopenia but excess body fat, may have a lower BMI known as the normal weight obesity compared to the older adult with good bone density and large muscle bulk, but an acceptable amount of body fat [40].

\section{Obesity and Fall Consequences}

There is now emerging evidence on the role obesity in fallsrelated injuries, hospitalizations and fractures. A study examining the effect of obesity on the falls-related injuries and disabilities following a fall have found that older adults with class 1 (BMI 30.0$34.9 \mathrm{~kg} / \mathrm{m}^{2}$ ) and class 2 (BMI $35.0-39.9 \mathrm{~kg} / \mathrm{m}^{2}$ ) obesity were more likely to develop disability following a fall compared to older adults of normal BMI [41]. Additionally, Fjeldstad, et al. have also proposed 
that older adults with obesity have a lower quality of life which may be explained by the excessive weight limits their mobility as well as the presence of multiple medical comorbidities which often co-exist with obesity [42]. As for fracture risk, traditionally, obesity was believed to be protective against fracture due to the excessive body fat that acts as a cushion [43]. However, evidence from recently published literature suggest that the association between obesity and fracture may be site-specific in which obesity may be protective against fractures in certain sites such as the hip and may be a risk factor against fractures in some sites such as the wrist and ankle [44]. In a large population based prospective study, the authors found that older women with increased body fat have a lower risk of fracture compared to men which may further indicate that fracture risk is sex-specific [45].

\section{Conclusion}

Obesity and falls' relationship specifically among older adults remain a grey area which requires further exploration. Current research is limited by the lack of a suitable definition or measurement for obesity in older adults. Further, there remains no concrete evidence for weight management strategies to reduce risk of falls among older adults. Given the global epidemic of obesity, preventing falls occurrences in older adults with obesity will further translate into a substantial socioeconomic benefit in a global scale. Additionally, with the new emerging type of obesity known as the sarcopenic obesity which is growing in the increasingly older population, further insight into and a better understanding of the role of obesity in falls risk in older adults is has now become an urgent imperative.

\section{Future research directions}

a) More appropriate definitions and methods of quantification of obesity in older adults are required

b) The relations between obesity with falls and falls consequences should be further determined in prospective studies with longer term follow-up

c) A better understanding of body compositions with increasing age and its relationship with obesity in older adults, may help address the obesity paradox

d) Intervention studies evaluating the safety of weight reduction strategies among older adults in terms of falls outcomes are required to determine any causal relationship between obesity and falls in older persons.

\section{References}

1. Jehan S, Zizi F, Pandi Perumal SR, Wall S, Auguste E, et al. (2017) Obstructive Sleep Apnea and Obesity: Implications for Public Health. Sleep Med Disord 1(4): 00019.

2. Gupta A, Kapil U, Khandelwal R, Khenduja P, Sareen N, et al. (2018) Prevalence and risk factors of underweight, overweight and obesity among a geriatric population living in a high-altitude region of rural Uttarakhand, India. Public Health Nutr 21(10): 1904-1911.

3. Frasca D, Blomberg BB, Paganelli R (2017) Aging, Obesity and Inflammatory Age-Related Diseases. Front Immunol 8: 1745.
4. (2018) World Health Organisation. Falls Fact Sheet.

5. Alex D, Khor HM, Chin AV, Hairi NN, Othman S, et al. (2018) Crosssectional analysis of ethnic differences in fall prevalence in urban dwellers aged 55 years and over in the malaysian elders longitudinal research study. BMJ Open 8(7).

6. Kim SY, KIM MS, SIM SY, Bunjung P, Choi HY (2016) Association Between Obesity and Falls Among Korean Adults: A Population-Based CrossSectional Study. Medicine 95(12): e3130.

7. Cho BY, Seo DC, Lin HC, Lohrmann DK, Chomistek AK (2018) BMI and Central Obesity with Falls Among Community-Dwelling Older Adults. Am J Prev Med 54(4): 59-66.

8. Neri SGR, Gadelha AB, Correia ALM, Pereira JC, Safons MP, et al. (2017) Association between obesity, risk of falls and fear of falling in older women. Revista Brasileira de Cineantropometria \& Desempenho Humano 19: 450-458.

9. (2018) Obesity and overweight Geneva. WHO.

10. Hajek A, Lehnert T, Ernst A, Lange C, Wiese B, et al. (2015) Prevalence and determinants of overweight and obesity in old age in Germany. BMC Geriatr 15(1): 83.

11. Yeom J, Kim JK, Crimmins EM (2009) Factors Associated with Body Mass Index(BMI) Among Older Adults: A Comparison Study of the U.S., Japan and Korea. Hanguk Nonyonhak 29(4): 1479-1500.

12. Stenholm S, Harris TB, Rantanen T, Visser M, Kritchevsky SB, et al. (2008) Sarcopenic obesity - definition, etiology and consequences. Curr Opin Clin Nutr Metab Care 11(6): 693-700.

13. Choi KM (2016) Sarcopenia and sarcopenic obesity. Korean J Intern Med 31(6): 1054-1060.

14. Dhargave P, Sendhilkumar R (2016) Prevalence of risk factors for falls among elderly people living in long-term care homes. J Clin Gerontol Geriatr 7(3): 99-103.

15. Worapanwisit T, Prabpai S, Rosenberg E (2018) Correlates of Falls among Community-Dwelling Elderly in Thailand. J of Aging Res 2018(2): 1-10.

16. Vieira LS, Gomes AP, Bierhals IO, Farías Antúnez S, Ribeiro CG, et al. (2018) Falls among older adults in the South of Brazil: prevalence and determinants. Revista de saude publica 52: 22.

17. Collerton J, Kingston A, Bond J, Davies K, Eccles MP, et al. (2012) The personal and health service impact of falls in 85-year olds: crosssectional findings from the Newcastle 85+ cohort study. PloS one 7(3): e33078.

18. Gale CR, Cooper C, Aihie Sayer A (2016) Prevalence and risk factors for falls in older men and women: The English Longitudinal Study of Ageing. Age Ageing 45(6): 789-794.

19. Bergen G, Stevens MR, Burns ER (2016) Falls and Fall Injuries Among Adults Aged $>/=65$ Years - United States, 2014. MMWR Morb Mortal Wkly Rep 65(37): 993-998.

20. Capon A, Di Lallo D, Mastromattei A, Pavoni N, Simeoni S (2007) Incidence and risk factors for accidental falls among general practice elderly patients in Latina, Central Italy. Epidemiologia e prevenzione 31(4): 204-211.

21. Cesari M, Landi F, Torre S, Onder G, Lattanzio F, et al. (2002) Prevalence and risk factors for falls in an older community-dwelling population. J Gerontol A Biol Sci Med Sci 57(11): 722-726.

22. Kioh S, Rashid A (2018) The prevalence and the risk of falls among institutionalised elderly in Penang, Malaysia. Med J Malaysia 73(4): 212219.

23. Azidah AK, Hasniza H, Zunaina E (2012) Prevalence of Falls and Its Associated Factors among Elderly Diabetes in a Tertiary Center, Malaysia. Curr Gerontol Geriatr Res 2012: 1-5. 
24. Graafmans WC, Ooms ME, Hofstee HM, Bezemer PD, Bouter LM, et al. (1996) Falls in the elderly: a prospective study of risk factors and risk profiles. Am j of epidemiol 143(11): 1129-1136.

25. Stenhagen M, Ekström H, Nordell E, Elmståhl S (2013) Falls in the general elderly population: A 3- and 6- year prospective study of risk factors using data from the longitudinal population study 'Good ageing in Skane'. BMC Geriatr 13(1): 81

26. Dos Reis KMC, de Jesus CAC (2015) Cohort study of institutionalized elderly people: fall risk factors from the nursing diagnosis. Revista latino-americana de enfermagem 23(6): 1130-1138.

27. Tan PJ, Khoo EM, Chinna K, Saedon NIz, Zakaria MI, et al. (2018) Individually-tailored multifactorial intervention to reduce falls in the Malaysian Falls Assessment and Intervention Trial (MyFAIT): A randomized controlled trial. PLOS ONE 13(8): e0199219.

28. Deandrea S, Bravi F, Turati F, Lucenteforte E, La Vecchia C, et al. (2013) Risk factors for falls in older people in nursing homes and hospitals. A systematic review and meta-analysis. Arch Gerontol Geriatr 56(3): $407-$ 415.

29. Tan MP, Kenny RA (2006) Cardiovascular assessment of falls in older people. Clin Interv Aging 1(1): 57-66.

30. Ambrose AF, Paul G, Hausdorff JM (2013) Risk factors for falls among older adults: A review of the literature. Maturitas 75(1): 51-61.

31. Aranda Gallardo M, Morales Asencio JM, Enriquez de Luna Rodriguez M, Vazquez Blanco MJ, Morilla Herrera JC, et al. (2018) Characteristics, consequences and prevention of falls in institutionalised older adults in the province of Malaga (Spain): a prospective, cohort, multicentre study. BMJ Open 8(2).

32. Mitchell RJ, Lord SR, Harvey LA, Close JCT (2014) Associations between obesity and overweight and fall risk, health status and quality of life in older people. Aust N Z J Public Health 38(1): 13-18.

33. Hooker ER, Shrestha S, Lee CG, Cawthon PM, Abrahamson M, et al. (2017) Obesity and Falls in a Prospective Study of Older Men: The Osteoporotic Fractures in Men Study. J Nutr Health Aging 29(7): 1235-1250.

34. Rossi Izquierdo M, Santos Perez Sa, FaraldoGarcia A, Vaamonde Sanchez Andrade I, et al. (2016) Impact of obesity in elderly patietns with postural instability. Aging Clin Exp Res 28(3): 423-428.

ISSN: 2574-1241

DOI: 10.26717/BJSTR.2019.13.002345

Maw Pin Tan. Biomed J Sci \& Tech Res

CC (i) This work is licensed under Creative Commons Attribution 4.0 License

Submission Link: https://biomedres.us/submit-manuscript.php
35. Mitchell RJ, Lord SR, Harvey LA, Close JC (2015) Obesity and falls in older people: mediating effects of disease, sedentary behavior, mood, pain and medication use. Arch Gerontol Geriatr 60(1): 52-58.

36. Sheehan KJ, O Connell, Matthew DL, Cunningham C, Crosby L, et al. (2013) The relationship between increased body mass index and frailty on falls in community dwelling older adults. BMC Geriatr 13(1): 132

37. Fauziana R, Jeyagurunathan A, Abdin E, Vaingankar J, Sagayadevan V, et al. (2016) Body mass index, waist-hip ratio and risk of chronic medical condition in the elderly population: results from the Well-being of the Singapore Elderly (WiSE) Study. BMC Geriatr 16(1): 125.

38. Price GM1, Uauy R, Breeze E, Bulpitt CJ, Fletcher AE (2006) Weight, shape, and mortality risk in older persons: elevated waist-hip ratio, not high body mass index, is associated with a greater risk of death. Am J Clin Nutr 84(2): 449-460.

39. Tan MP, Bansal SK (2012) The Arm Span to Height Relationship and Its Health Implications. In: Preedy VR, editor. Handbook of Anthropometry: Physical Measures of Human Form in Health and Disease. New York, NY: Springer New York, USA, pp. 741-54.

40. Romero Corral A, Somers VK, Sierra Johnson J, Korenfeld Y, Boarin S, et al. (2010) Normal weight obesity: A risk factor for cardiometabolic dysregulation and cardiovascular mortality. Eur Heart J 31(6): 737-746.

41. Himes CL, Reynolds SL (2012) Effect of Obesity on Falls, Injury, and Disability. J Am Geriatr Soc 60(1): 124-129.

42. Fjeldstad C, Fjeldstad AS, Acree LS, Nickel KJ, Gardner AW (2008) The influence of obesity on falls and quality of life. Dyn Med 7(1): 4.

43. Bouchard DR, Pickett W Fau Janssen I, Janssen I (2010) Association between obesity and unintentional injury in older adults. Obes Facts 3(6): 363-369.

44. Johansson H, Fau KJ, Fau OA, Fau ME, Fau CR, et al. (2014) A meta-analysis of the association of fracture risk and body mass index in women. J Bone Miner Res 29(1): 223-233.

45. Moayyeri A, Luben RN, Wareham NJ, Khaw KT (2011) Body fat mass is a predictor of risk of osteoporotic fractures in women but not in men: a prospective population study. J Intern Med 271(5): 472-480.

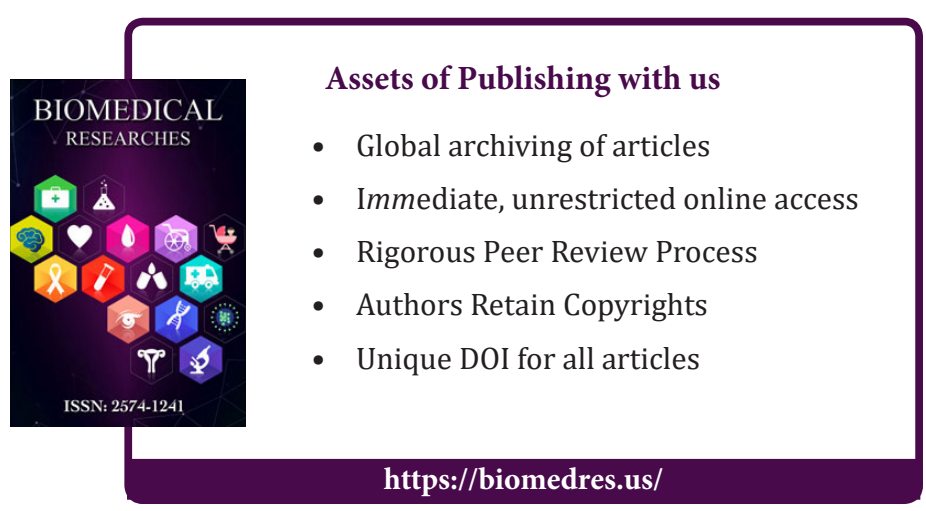

Cite this article: Sheng Hui Kioh, Sumaiyah Mat, Phyo Kyaw Myint, Maw Pin Tan. Could Obesity be Linked to Falls in Older Adults?. Biomed J 